\title{
VARIAÇÃO LIGNO-ANATÔMICA EM MUDAS DE Eucalyptus grandis (Hill ex Maiden) TRATADAS COM REGULADORES DE CRESCIMENTO
}

\author{
Regina Paula Willemen Pereira ${ }^{1}$, Heber dos Santos Abreu², Maria Beatriz de Oliveira Monteiro, \\ Natália Dias de Souza ${ }^{4}$
}

(recebido: 13 de março de 2010; aceito: 28 de abril de 2011)

\begin{abstract}
RESUMO: Neste trabalho, objetivou-se analisar a relação dos reguladores de crescimento GA e BAP na lignificação e, consequentemente no diâmetro das fibras de plantas de Eucalyptus grandis aos seis meses de idade. Estudos anatômicos, bioquímicos e genéticos em decorrência da aplicação exógena de reguladores de crescimento na fase de desenvolvimento do vegetal, têm sido cada vez mais enfatizados. Alguns desses estudos têm obtido avanço no que se refere à interação dos hormônios vegetais em relação à anatomia e ao processo de lignificação. A aplicação dos reguladores de crescimento GA, e BAP foi realizada isoladamente ou combinados nas respectivas concentrações: $\mathrm{GA}_{3}(49,13 \mu \mathrm{M}$ e 98,26 $\mu \mathrm{M})$; BAP $(111 \mu \mathrm{M}$ e $222 \mu \mathrm{M})$, em mudas de Eucalyptus grandis até seis meses de idade. Análises químicas e anatômicas foram realizadas com o segmento caulinar das plantas tratadas. Para quantificar o teor de lignina pelo método Klason, as amostras foram livres para a retirada de extrativos e proteínas. Para a mensuração do diâmetro das fibras, as amostras, após sua dissociação, foram analisadas por microscopia ótica. O teor de lignina variou entre 23,37 a 29,64\% e o diâmetro de fibra variou entre 13,33 a 20,39 $\mu \mathrm{m}$. Também, pelos resultados, foi possível visualizar, com o tratamento $\mathrm{G}_{[1]} \mathrm{C}_{[1]}\left(49,13\right.$ de $\mathrm{GA}_{3}$ com $111 \mu \mathrm{M}$ de BAP) que o teor de lignina reduziu em 21,2\% em relação ao controle, e o diâmetro de fibra obteve o menor aumento em relação aos outros tratamentos.
\end{abstract}

Palavras-chave: Lignina, fibra, giberelina, citocinina.

\section{LIGNOANATOMICAL VARIATION IN SEEDLINGS OF Eucalyptus grandis (Hill ex Maiden) TREATED WITH GROWTH REGULATORS}

\begin{abstract}
The aim of this study was to analyze the influence of growth regulators $\mathrm{GA}_{3}$ and BAP on lignification and consequently on the diameter of fibers in Eucalyptus grandis plants at age six months. Anatomical, biochemical and genetic studies after exogenous application of growth regulators during the development phase have been increasingly explored. Some of these studies have achieved progress regarding the interaction of plant hormones with the anatomy and the lignification process in plants. The application of growth regulators $G A_{3}$ and $B A P$ was done separately or combined in the following concentrations: $G A_{3}(49.13 \mu M$ and $98.26 \mu M)$, $B A P\left(111 \mu M\right.$ and $\left.222^{3} \mu M\right)$, using seedlings of Eucalyptus grandis at age up to six months. Chemical and anatomical analyses were performed on the stem segment of plants subjected to treatment. To quantify lignin content by the Klason method, samples were subjected to removal of extractives and proteins. To measure fiber diameter, once dissociated, samples were analyzed by optical microscopy. The lignin content ranged between $23.37 \%$ and $29.64 \%$ and fiber diameter ranged between $13.33 \mu \mathrm{m}$ and $20.39 \mu \mathrm{m}$. From results it was possible to visualize, with the $G_{[I I} C_{\text {II }}$ treatment $\left(49.13 \mu \mathrm{M}\right.$ of $\mathrm{GA}_{3}$ with $111 \mu \mathrm{M}$ of BAP) that lignin content dropped by $21.2 \%$ in relation to the control treatment, and that fiber diameter had the smallest increase in relation to other treatments.
\end{abstract}

Key words: Lignin, fiber, gibberellin, cytokinin.

\section{INTRODUÇÃO}

As fibras do eucalipto possuem características de interesse para a indústria, e o Eucalyptus grandis destaca-se entre as espécies mais utilizadas. A indústria de celulose e de chapas de fibras utiliza-o com destaque, desempenhando um importante papel para tais finalidades (BRASIL; FERREIRA, 1972). Dessa forma, os aspectos que podem interferir nas características das fibras, têm importância para diversos segmentos florestais. O processo de lignificação é um importante aspecto de implicação no produto final. Então, é de interesse analisar e avaliar as possibilidades de intervenção na lignificação para estudos e possíveis aplicabilidades na utilização das fibras. Qualquer efeito no aspecto bioquímico na lignificação de fibras, como resultado de tratamento com giberelina, pode ser de possível valor comercial (ATAL, 1961).

\footnotetext{
${ }^{1}$ Engenheira Florestal, Doutora em Ciências Ambientais e Florestais - Departamento de Produtos Florestais - Instituto de Florestas - Universidade Federal Rural do Rio de Janeiro/UFRRJ - Br 465, Km 07 - 23890-000 - willemen@bol.com.br

${ }^{2}$ Engenheiro Florestal, Professor Doutor em Química Orgânica - Departamento de Produtos Florestais - Instituto de Florestas - Universidade Federal Rural do Rio de Janeiro/UFRRJ - Br 465, Km 07 - 23890-000 - abreu@ufrrj.br

${ }^{3}$ Engenheira Florestal, Doutora em Ciências Ambientais e Florestais - Departamento de Produtos Florestais - Instituto de Florestas - Universidade Federal Rural do Rio de Janeiro/UFRRJ - Br 465, Km 07 - 23890-000 - betyka@ufrrj.br

${ }^{4}$ Engenheira Florestal, Professora Mestre em Ciências Ambientais e Florestais - Departamento de Produtos Florestais - Instituto de Florestas Universidade Federal Rural do Rio de Janeiro/UFRRJ - Br 465, Km 07 - 23890-000 - natdias@ufrrj.br
}

Cerne, Lavras, v. 17, n. 3, p. 369-375, jul./set. 2011 
Fica evidente a necessidade de explorar a amplitude das conseqüências do processo de lignificação, pelo estudo anatômico para melhorar a compreensão da lignina e prover um futuro de possibilidades para a intervenção e produção de plantas com características exploráveis comercialmente.

Há um grande interesse, relatado várias vezes na literatura que relaciona a interferência dos fitohormônios na lignificação, por conseguinte, nas características celulares. Segundo Liu et al. (2001), as mudanças na configuração e conformação durante o crescimento e desenvolvimento das plantas, estão diretamente ou indiretamente relacionadas com os fitohormônios. Vários tipos de células em uma planta têm funções distintas. As fibras, por exemplo, são células longas e estreitas com paredes espessas e lignificadas, com função de sustentação, encontradas no xilema e em floema oriunda das iniciais axiais do câmbio (ALONI, 1990). Aloni (1979) mostrou que o papel das folhas na diferenciação de fibras de floema primário em Coleus pode ser substituído por aplicações exógenas de combinação de AIA (ácido 3-indol-acético) e $\mathrm{GA}_{3}$ (ácido giberélico), considerando que o $\mathrm{GA}_{3}$, aplicado sozinho não mostrou efeito visível sobre a formação da fibra. $\mathrm{O} \mathrm{GA}_{3}$ somente afeta a diferenciação da fibra de floema na presença de auxina. A combinação de AIA com $\mathrm{GA}_{3}$ contribui para a diferenciação de fibra do floema, qualitativamente e quantitativamente (ALONI, 1979). Quando várias combinações de ambos os reguladores de crescimento foram aplicadas em caules decapitados, com concentrações altas de AIA estimularam a diferenciação rápida de fibras proporcionando paredes secundárias espessas, considerando que níveis altos de $\mathrm{GA}_{3}$ produzem fibras longas com paredes delgadas (ALONI, 1979).

Em experimentos em cultura de tecido, a citocinina foi reconhecida por estimular a divisão celular e por controlar a diferenciação de elementos traqueoidais (DALESSANDRO; ROBERTS, 1971) e de fibras do xilema secundário (ALONI, 1982). O papel da citocinina foi estudado também durante a diferenciação de células de plantas de Helianthus annuus (SAKS et al., 1984). Aloni (1982) mostrou que a citocinina é requerida durante as fases iniciais de diferenciação da fibra.

Conduziu-se este trabalho, com o objetivo de verificar o efeito da aplicação de reguladores de crescimento no diâmetro de fibra e no processo de lignificação de mudas de Eucalyptus grandis, aos seis meses, tratadas com ácido giberélico $\left(\mathrm{GA}_{3}\right)$ e 6-benzilaminopurina (BAP).

Cerne, Lavras, v. 17, n. 3, p. 369-375, jul./set. 2011

\section{MATERIAL E MÉTODOS}

A primeira fase do experimento foi realizada em ambiente de viveiro. As sementes foram germinadas em tubetes, preenchidos com o substrato $(60 \%$ de composto orgânico, $20 \%$ de argila, $10 \%$ de areia e $10 \%$ de vermiculita). Foram utilizadas sementes certificadas de Eucalyptus grandis. Após 80 dias de crescimento, realizouse a repicagem, transferindo para 45 tubetes com capacidade de 3,8 L. Cada tubete continha apenas uma planta. A segunda fase foi desenvolvida na casa de vegetação onde foram realizadas as aplicações com os reguladores de crescimento.

A primeira aplicação foi feita aos 90 dias (segunda quinzena do mês de junho). Nas aplicações, cada planta recebeu, por pulverização, uma solução aquosa de reguladores de crescimento. Foram utilizados os seguintes tratamentos, envolvendo o GA3 e o BAP: $49,13 \mu \mathrm{M}$ de GA3; 98,26 $\mu \mathrm{M}$ de GA3; $111 \mu \mathrm{M}$ de BAP; $222 \mu \mathrm{M}$ de BAP; $49,13 \mu \mathrm{M}$ de GA3 + $111 \mu \mathrm{M}$ de BAP; $49,13 \mu \mathrm{M}$ de GA3 + $222 \mu \mathrm{M}$ de BAP; $98,26 \mu \mathrm{M}$ de GA3 + $111 \mu \mathrm{M}$ de BAP; 98,26 $\mu \mathrm{M}$ de GA3 $+222 \mu \mathrm{M}$ de BAP; $0 \mu \mathrm{M}$ de GA3 $+0 \mu \mathrm{M}$ de $\mathrm{BAP}$ nas respectivas concentrações, com cinco repetições para cada tratamento, com delineamento estatístico inteiramente casualizado. Foi realizado um total de sete aplicações com um intervalo de dez dias para cada uma.

Cada tubete recebeu $350 \mathrm{~mL}$ de água, durante toda a segunda fase do experimento, sendo que nos dias mais quentes foram feitas duas irrigações. As aplicações eram iniciadas sempre às 5 horas da manhã. Para otimizar a absorção das soluções de reguladores, foi adicionado a essas soluções um agente tenso ativo conhecido comercialmente por Adesil@.

\subsection{Análise citológica}

O primeiro segmento das bases dos caules (a partir de $1 \mathrm{~cm}$ ) foram usados para os cortes transversais. Para este trabalho, foi utilizado o segundo segmento dos caules $(1 \mathrm{~cm})$ imersos em frascos contendo solução conservante: $150 \mathrm{~mL}$ de glicerina, $300 \mathrm{~mL}$ de álcool e $400 \mathrm{~mL}$ de água.

Para a dissociação de elementos celulares, uma amostra de cada tratamento foi submersa em solução de água oxigenada e ácido acético (1:1) (método de Franklin) (FRANKLIN, 1945), ficando por 48 horas na estufa a $60{ }^{\circ} \mathrm{C}$. Depois o material foi dissociado, lavado com água bidesionizada e corado com safranina alcoólica a $1 \%$. As mensurações microscópicas para diâmetro de fibras foram realizadas e documentadas por fotomicrografias obtidas ao microscópio fotônico Olympus BH-2. 


\subsection{Preparação do material para análise química}

A parte do caule utilizada para a análise química foi a retirada da parte superior dos segmentos usados para os estudos anatômicos até antes do terceiro entrenó. Esses segmentos de caule reservados para a análise química (cinco repetições de cada tratamento) foram descascados e acondicionados em câmara fria e depois moídos em Moinho de Facas (Willie) mod.40A 110/220V e peneirado em Agitador de Peneiras Produteste Mod.T.

\subsection{Obtenção do material lignocelulósico livre de extrativos}

Uma amostra com aproximadamente $3 \mathrm{~g}$ da fração do material foi homogeneizada por um conjunto de peneiras que atravessou a malha 40 ASTM e ficou retido na malha 60 ASTM. Essa amostra passou por uma extração contínua de vinte e quatro horas para cada solvente em um extrator do tipo Soxhlet, utilizando os solventes segundo a série eluitrópica: ciclo hexano, acetato de etila, metanol e uma extração com água bideionizada (BROWNING, 1967). Após o término da extração, o material solúvel foi concentrado em um evaporador rotatório, armazenado em um dessecador até ficar completamente seco.

\subsection{Obtenção do material livre de proteína}

Uma amostra de material livre de extrativos com $1 \mathrm{~g}$ foi colocada em erlenmeyer de $250 \mathrm{~mL}$, sendo um erlenmeyer por tratamento com $40 \mathrm{~mL}$ de solução de pepsina contendo $1 \%$ em ácido clorídrico $0.1 \mathrm{~N}$ que ficaram em banho-maria a $40{ }^{\circ} \mathrm{C}$ por 13 horas para padronizar todas as amostras (BREMMER, 1965). Após esse período as amostras foram filtradas em um funil de placa sob vácuo, onde foram lavadas duas vezes com $48 \mathrm{~mL}$ para cada lavagem com água quente; $12,8 \mathrm{~mL}$ de ácido sulfúrico $\left(\mathrm{H}_{2} \mathrm{SO}_{4}\right)(5 \%)$. Em seguida, a amostra foi tranferida para um balão de vidro com $240 \mathrm{~mL}$ de $\mathrm{H}_{2} \mathrm{SO}_{4}$ $(5 \%)$ e colocada em refluxo por uma hora. Novamente foi transferida para um filtro e sob vácuo, onde a amostra foi lavada três vezes com $48 \mathrm{~mL}$ de água bideionizada quente por duas vezes com $32 \mathrm{~mL}$ de etanol e duas vezes com 24 $\mathrm{mL}$ de éter, ambas, para cada lavagem.

\subsection{Lignina insolúvel de Klason}

Para a obtenção da lignina de Klason, foi utilizada metodologia segundo Browning (1967). Uma porção com 300mg de amostra seca (livre de extrativos e proteína) foi transferida para um tubo de ensaio, adicionando-se $3 \mathrm{~mL}$ de ácido sulfúrico a $72 \%$. A amostra foi macerada com um macerador mecânico (Potters - B. Braun Biotech
Internacional) por 3 minutos e maceração manual contínua durante 1 hora. Os tubos de ensaio durante a maceração foram mantidos a uma temperatura entre 25 a $30{ }^{\circ} \mathrm{C}$ em banho-maria. O material foi transferido para um balão (um para cada tratamento) de $250 \mathrm{~mL}$ e diluído utilizando-se solução de ácido sulfúrico, adicionando $84 \mathrm{~mL}$ de água bideionizada. O material ficou em refluxo por $4 \mathrm{~h}$ seguidas e foi em repouso para sedimentação da lignina. A solução de lignina ácida foi filtrada em um cadinho de porcelana e colocada em estufa a $105^{\circ} \mathrm{C}$.

\section{RESULTADOS E DISCUSSÃO}

Todos os dados analisados tiveram distribuição normal quando submetidos ao teste de KolmogorovSmirnov, ao nível de significância de 5\% para o diâmetro da fibra e teor de lignina. Foi também verificada a homogeneidade das variâncias, pelo teste de Bartlett com a mesma significância.

A análise de variância e o teste de Tukey permitiram estabelecer que em presença de ambas as concentrações de $\mathrm{GA}_{3}$ (tratamentos $\mathrm{G}_{[1]}$ e $\mathrm{G}_{[2]}$ ) e também na combinação de $\mathrm{GA}_{3}$ e BAP (tratamento $\mathrm{G}_{[2]} \mathrm{C}_{[2]}$ ) houve um aumento no diâmetro da fibra em relação ao controle (Figura $1 \mathrm{e}$ Tabela 1). Isso coaduna com o resultado de pesquisa realizada com Pinus radiata, em que um baixo teor de giberelina foi adicionado ao caule dessa planta, além de contribuir para a formação de xilema com relação aos diferentes características, houve também um aumento no diâmetro dos traqueídes (PHARIS et al., 1981).

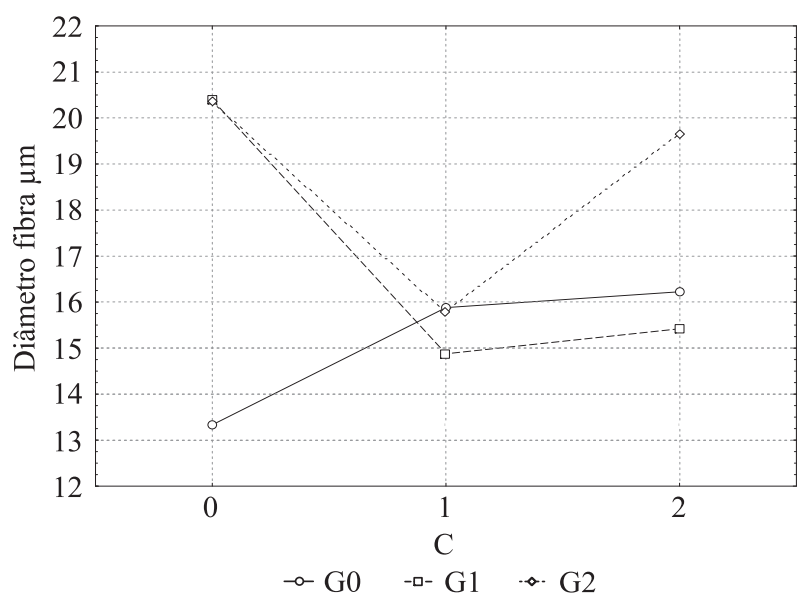

Figura 1 - Valores obtidos com os tratamentos isolados e combinados de giberelina e citocinina para o diâmetro da fibra.

Figure 1 - Values obtained using separate and combined treatments of gibberellin and cytokinin for fiber diameter.

Cerne, Lavras, v. 17, n. 3, p. 369-375, jul./set. 2011 
Tabela 1 - Comparações múltiplas entre as médias do diâmetro de fibra $(\mu \mathrm{m})$.

Table 1 -Multiple comparisons between means of fiber diameter ( $\mu m)$.

\begin{tabular}{cccc}
\hline \multirow{2}{*}{ BAP } & \multicolumn{3}{c}{$\mathrm{GA}_{3}$} \\
\cline { 2 - 4 } & $\mathrm{G}_{[0]}$ & $\mathrm{G}_{[1]}$ & \multicolumn{1}{c}{$\mathrm{G}_{[2]}$} \\
\hline $\mathrm{C}_{[0]}$ & $13,33 \mathrm{aA}$ & $20,39 \mathrm{bA}$ & $20,37 \mathrm{bA}$ \\
$\mathrm{C}_{[1]}$ & $15,88 \mathrm{aB}$ & $14,87 \mathrm{aB}$ & $15,78 \mathrm{aB}$ \\
$\mathrm{C}_{[2]}$ & $16,22 \mathrm{aB}$ & $15,42 \mathrm{aB}$ & $19,64 \mathrm{bAC}$ \\
\hline
\end{tabular}

Nota: Letras minúsculas distintas mostram as diferenças significativas para o teste de Tukey entre colunas e letras maiúsculas entre linhas, a 5\% de significância; $\mathrm{GA}_{3}$ (ácido giberélico), $\mathrm{G}_{[0]}$ (ausência de $\mathrm{GA}_{3}$ ), $\mathrm{G}_{[1]}$ (presença de $49,13 \mu \mathrm{M}$ de $\mathrm{GA}_{3}$ ), $\mathrm{G}_{[2]}$ (presença de 98,26 $\mu \mathrm{M}$ de $\mathrm{GA}_{3}$ ), $\mathrm{C}_{[0]}$ (ausência de BAP), $\mathrm{C}_{[1]}^{[2]}$ (presença de $111 \mu \mathrm{M}$ de BAP), $\mathrm{C}_{[2]}$ (presença de $222 \mu \mathrm{M}$ de BAP).

As plantas dos tratamentos $\mathrm{C}_{[1]}$ e $\mathrm{C}_{[2]}$ com BAP também aumentaram o diâmetro da fibra $(15,88 \mu \mathrm{m}$ e $16,22 \mu \mathrm{m})$, respectivamente, em relação ao controle $(13,33 \mu \mathrm{m})$, porém, o aumento do diâmetro das fibras proporcionado pela presença dos tratamentos com o $\mathrm{GA}_{3}$ utilizado isoladamente (tratamentos $\mathrm{G}_{[1]}$ e $\mathrm{G}_{[2]}$ ), foi superior a todos os tratamentos.

Segundo Li (1992), o GA foi utilizado em estudos para o aumento da produção de fibras de rami (Boehmeria nivea (L.) Gaudich.), mas, como conseqüência, ocorreu um aumento no diâmetro da fibra. Efeito similar foi percebido nesse trabalho com o $E$. grandis quando as plantas foram tratadas com as duas diferentes concentrações de $\mathrm{GA}_{3}$ (tratamentos $\mathrm{G}_{[1]}$ e $\mathrm{G}_{[2]}$ ), isto é, proporcionaram aumentos no diâmetro das fibras.

Os tratamentos $\mathrm{G}_{[1]} \mathrm{C}_{[1]}$ e $\mathrm{G}_{[1]} \mathrm{C}_{[2]}$ não apresentaram diferença significativa entre si, porém, ambos diferenciaramse do tratamento $G_{[1]}$. Reguladores de crescimento como a giberelina $\left(\mathrm{GA}_{3}\right)$ afetam a produtividade e qualidade das fibras de rami (Boemheria nivea (L.) Gaud.) (WANG; HE, 1992).

Os resultados mostraram que, quando adicionado BAP nas concentrações utilizadas nesse trabalho $(111 \mu \mathrm{M}$ ou $222 \mu \mathrm{M})$, juntamente com a concentração de 49, $13 \mu \mathrm{M}$ de $\mathrm{GA}_{3}$, que caracterizou os tratamentos $\mathrm{G}_{[1]} \mathrm{C}_{[1]}$ e $\mathrm{G}_{[1]} \mathrm{C}_{[2]}$ $(14,87 \mu \mathrm{m}$ e $15,42 \mu \mathrm{m}$ respectivamente), ambos reduziram significativamente o diâmetro de fibra comparado com o tratamento $G_{[1]}(20,39 \mu \mathrm{m})$. Já o dobro da concentração do $\mathrm{GA}_{3}(98,26 \mu \mathrm{M})$, utilizado, isoladamente no tratamento $\mathrm{G}_{[2]}$, não proporcionou diferença significativa para o diâmetro de fibra em relação ao tratamento $\mathrm{G}_{[1]}$. Porém, ambos, $G_{[1]}$ e $G_{[2]}$ diferenciaram-se significativamente em relação ao controle $(13,33 \mu \mathrm{m})$, com um aumento no diâmetro da fibra muito significante (Figura 1 e Tabela 1). Plantas de linho tratadas com giberelina apresentaram aumento no diâmetro de fibras (ATAL, 1961).

Os tratamentos combinados $\mathrm{G}_{[1]} \mathrm{C}_{[1]}, \mathrm{G}_{[1]} \mathrm{C}_{[2]}$ e $\mathrm{G}_{[2]}$ $\mathrm{C}_{[1]}$ não apresentaram diferença significativa entre si no diâmetro da fibra, mas, diferiram-se em relação ao controle e ao $\mathrm{G}_{[2]} \mathrm{C}_{[2]}$ (Figura 1 e Tabela 1). Porém, quando a concentração de ambos os reguladores foram dobradas e combinadas, o diâmetro de fibra aumentou o que caracterizou o tratamento $\mathrm{G}_{[2]} \mathrm{C}_{[2]}$ e tornou-se semelhante estatisticamente ao tratamento $\mathrm{G}_{[2]}$ e ao $\mathrm{G}_{[1]}$.

As análises químicas das plantas de E. grandis após sete aplicações com uma concentração de 49,13 $\mu \mathrm{M}$ de $\mathrm{GA}_{3}$ aplicada isoladamente, tratamento $\mathrm{G}_{[1]}$, mostraram que o teor de lignina reduziu em relação ao controle. Entretanto, quando essa concentração foi dobrada (98,26 $\mu \mathrm{M})$ no tratamento $\mathrm{G}_{[2]}$, houve uma redução de lignina mais significativa $(23,42 \%)$ em relação ao tratamento $\mathrm{G}_{[1]}(27,74 \%)$ e ao controle $(29,64 \%)$. Demonstrando que a atuação desse regulador de crescimento $\left(\mathrm{GA}_{3}\right)$ atuou como inibidor da biossíntese de lignina em ambas as concentrações $\left(\mathrm{G}_{[1]}\right.$ e $\left.\mathrm{G}_{[2]}\right)$ e com a concentração maior $\left(G_{[2]}\right)$, reduziu mais satisfatoriamente em relação a menor concentração utilizada $\left(\mathrm{G}_{[1]}\right)$.

Entretanto, o inverso ocorreu em hipocótilos de Prunus spachiana quando o $\mathrm{GA}_{3}$ foi utilizado isoladamente, pois, estimulou a produção de lignina (NAKAMURA et al., 1994).

Os tratamentos que utilizaram o BAP isoladamente $\left(\mathrm{C}_{[1]}\right.$ e $\left.\mathrm{C}_{[2]}\right)$ também apresentaram redução em relação ao controle. $\mathrm{O}$ tratamento $\mathrm{C}_{[1]}$ apresentou uma maior redução maior em relação ao controle e também ao tratamento $\mathrm{C}_{[2]}$.

Já, em relação aos tratamentos que combinaram o $\mathrm{GA}_{3}$ com o BAP, não houve diferença entre o tratamento $\mathrm{G}_{[2]} \mathrm{C}_{[2]}$ e $\mathrm{G}_{[0]} \mathrm{C}_{[0]}$ (controle). Entretanto, o tratamento $\mathrm{G}_{[2]} \mathrm{C}_{[1]}$ apresentou uma maior redução do teor de lignina em relação ao tratamento $\mathrm{G}_{[2]} \mathrm{C}_{[2]}$ e ao controle. Isso demonstra que a concentração de $111 \mu \mathrm{M}$ de BAP foi preponderante, isto é, teve um efeito decisivo quando combinada com a concentração de 98,26 $\mu \mathrm{M}$ de $\mathrm{GA}_{3}$.

Os resultados apresentaram também que quando as plantas foram tratadas com uma combinação de 49,13 $\mu \mathrm{M}$ mais $111 \mu \mathrm{M}$ de BAP, isto é, o tratamento $\mathrm{G}_{[1]} \mathrm{C}_{[1]}$, houve uma maior redução no teor de lignina em relação ao tratamento $G_{[1]}$ e controle (Figura 2 e Tabela 2). No entanto, quando foi utilizado o dobro da concentração de BAP, isto é, $222 \mu \mathrm{M}$ juntamente com 49,13 $\mu \mathrm{M}$ de 


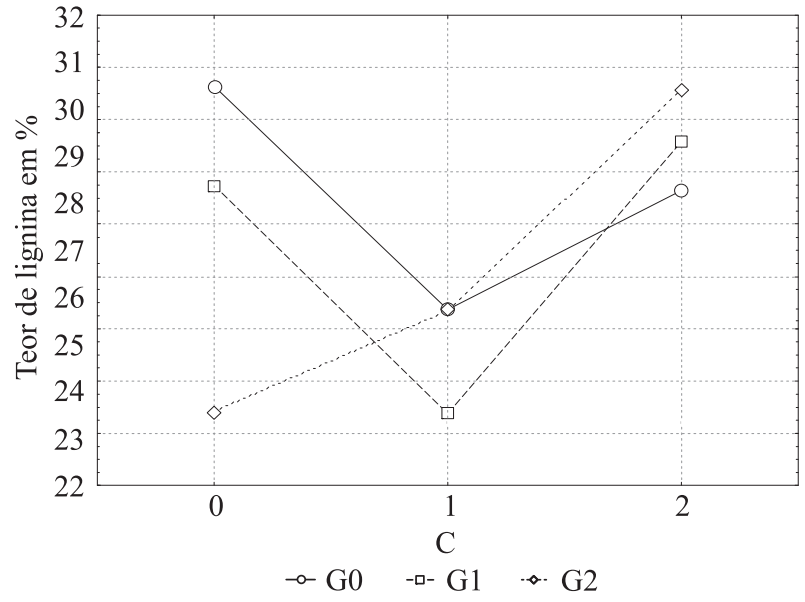

Figura 2 - Valores obtidos com os tratamentos isolados e combinados de giberelina e citocinina para o teor de lignina.

Figure 2 - Values obtained using separate and combined treatments of gibberellin and cytokinin for lignin content.

Tabela 2 - Comparações múltiplas entre as médias do teor de lignina insolúvel Klason (\%).

Table 2 - Multiple comparisons between means of insoluble Klason lignin content (\%).

\begin{tabular}{cccc}
\hline \multirow{2}{*}{ BAP } & \multicolumn{3}{c}{$\mathrm{GA}_{3}$} \\
\cline { 2 - 4 } & $\mathrm{G}_{[0]}$ & $\mathrm{G}_{[1]}$ & $\mathrm{G}_{[2]}$ \\
\hline $\mathrm{C}_{[0]}$ & $29,64 \mathrm{aA}$ & $27,74 \mathrm{bA}$ & $23,42 \mathrm{cA}$ \\
$\mathrm{C}_{[1]}$ & $25,36 \mathrm{aB}$ & $23,37 \mathrm{bB}$ & $25,35 \mathrm{aB}$ \\
$\mathrm{C}_{[2]}$ & $27,64 \mathrm{aC}$ & $28,57 \mathrm{bC}$ & $29,57 \mathrm{cC}$ \\
\hline
\end{tabular}

Nota: Letras minúsculas distintas mostram as diferenças significativas para o teste de Tukey entre colunas e letras maiúsculas entre linhas, a 5\% de significância; $\mathrm{GA}_{3}$ (ácido giberélico), $\mathrm{G}_{[0]}$ (ausência de $\mathrm{GA}_{3}$ ), $\mathrm{G}_{[1]}$ (presença de $49,13 \mu \mathrm{M}$ de $\mathrm{GA}_{3}$ ), $\mathrm{G}_{[2]}$ (presença de 98,26 $\mu \mathrm{M}$ de $\mathrm{GA}_{3}$ ), $\mathrm{C}_{[0]}$ (ausência de BAP), $\mathrm{C}_{[1]}^{[2]}$ (presença de $111 \mu \mathrm{M}$ de BAP), $\mathrm{C}_{[2]}$ (presença de $222 \mu \mathrm{M}$ de BAP).

$\mathrm{GA}_{3}(\mathrm{G}[1] \mathrm{C}[2])$, o teor de lignina aumentou em relação ao tratamento G[1]C[1]. Dessa forma, ficou estabelecido um domínio do efeito do regulador de crescimento BAP na concentração $111 \mu \mathrm{M}$ independente das concentrações utilizadas do $\mathrm{GA}_{3}(49,13 \mu \mathrm{M} \mathrm{e} 98,26 \mu \mathrm{M})$, pois, em ambos os casos $\left(\mathrm{G}_{[1]} \mathrm{C}_{[1]}\right.$ e $\left.\mathrm{G}_{[2]} \mathrm{C}_{[1]}\right)$ a redução do teor de lignina foi mais significativa, sendo assim, houve uma superioridade no efeito sinergístico do BAP sobre o $\mathrm{GA}_{3}$ em plantas de E. grandis com seis meses de idade.

As análises químicas e anatômicas revelaram que, apesar das diferentes concentrações de BAP utilizadas isoladamente, as quais caracterizaram os tratamentos
$\mathrm{C}_{[1]}$ e $\mathrm{C}_{[2]}$ apresentarem entre si diferença significativa em relação ao teor de lignina (Figura 2 e Tabela 2) o mesmo não ocorreu para o diâmetro de fibra, isto é, foram estatisticamente semelhantes (Figura 1 e Tabela 1). Porém, ambos os tratamentos $\mathrm{C}_{[1]}$ e $\mathrm{C}_{[2]}(15,88 \mu \mathrm{m}$ e $16,22 \mu \mathrm{m}$ respectivamente) apresentaram diferença significativa em relação ao controle $(13,33 \mu \mathrm{m})$ para o diâmetro de fibra. Os resultados apresentaram também a seguinte relação, quando foi adicionado à concentração de $111 \mu \mathrm{M}$ de $\mathrm{BAP}$ a uma concentração de $98,26 \mu \mathrm{M}$ de $\mathrm{GA}_{3}\left(\mathrm{G}_{[2]} \mathrm{C}_{[1]}\right)$, este não apresentou diferença significativa em relação ao tratamento $\mathrm{C}_{[1]}(111 \mu \mathrm{M}$ de BAP) nem para o teor de lignina, nem para $o$ diâmetro de fibra.

Para o teor de lignina o controle $\left(\mathrm{G}_{[0]} \mathrm{C}_{[0]}\right)$ não diferiu estatisticamente dos tratamentos $\mathrm{G}_{[1]} \mathrm{C}_{[2]}, \mathrm{G}_{[2]} \mathrm{C}_{[2]}$, tendo valor maior que todos os outros tratamentos, sendo que para o diâmetro da fibra o controle diferiu de todos os tratamentos apresentando o menor valor.

$\mathrm{Na}$ Figura 3, é possível perceber que mesmo quando a concentração de $\mathrm{GA}_{3}$ foi dobrada (do tratamento $\mathrm{G}_{[1]}$ para o $\mathrm{G}_{[2]}$, o diâmetro da fibra manteve-se constante, apesar da redução no teor de lignina. Entretanto, nos tratamentos apenas com citocinina (BAP), os diâmetros de fibra foram menores em relação aos tratamentos que usaram giberelina $\left(\mathrm{GA}_{3}\right)$ isoladamente.

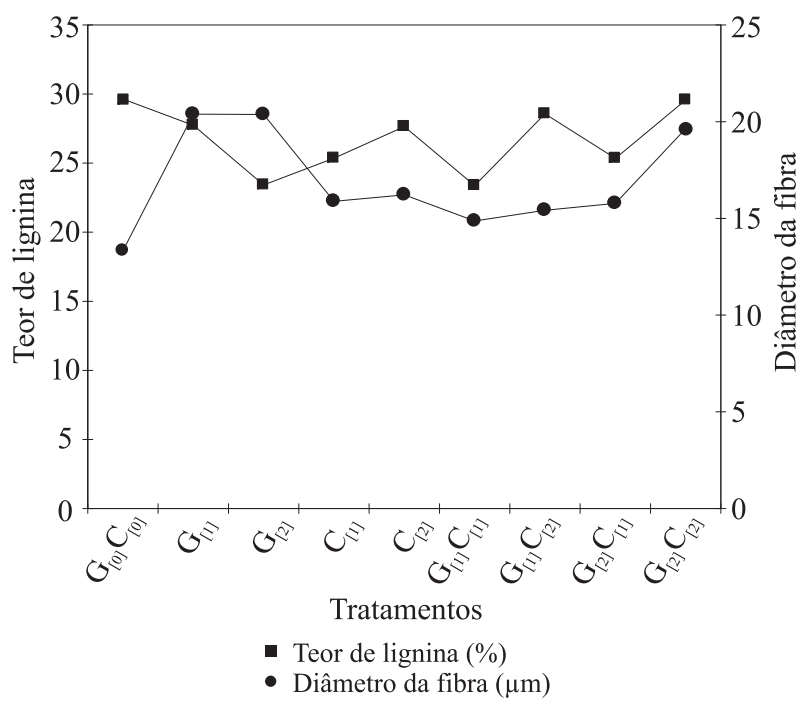

Figura 3 - Relação do teor de lignina com o diâmetro da fibra em plantas de Eucalyptus grandis tratadas com giberelina e citocinina.

Figure 3 - Relationship between lignin content and fiber diameter in Eucalyptus grandis plants treated with gibberellin and cytokinin.

Cerne, Lavras, v. 17, n. 3, p. 369-375, jul./set. 2011 
A aplicação exógena de reguladores de crescimento pode esclarecer questionamentos no que se refere à dinâmica dos papéis endógenos dos hormônios vegetais e dessa forma contribuir para o manejo de florestas e de suas finalidades para o produto final. $\mathrm{O}$ aumento da densidade básica da madeira sofre interferência direta da diminuição do diâmetro da fibra (SANTOS, 2005).

O experimento mostrou que a alteração dos níveis endógenos de giberelina em plantas transgênicas não somente influenciaram no crescimento da planta como também no teor de lignina (BIEMELT et al., 2004).

\section{CONCLUSÕES}

Os reguladores de crescimento $\left(\mathrm{GA}_{3}\right.$ e BAP) mostraram-se eficientes para alterar o teor de lignina e o diâmetro da fibra, em plantas de Eucalyptus grandis aos seis meses de idade, podendo ser utilizados como ferramentas modeladoras em anatomia e química da madeira.

\section{AGRADECIMENTOS}

Os autores agradecem à CAPES, pela bolsa concedida.

\section{REFERÊNCIAS}

ALONI, R. Role of auxin and gibberellin in controlling lignin formation in primary phloem fibers and in xylem of Coleus blumei stems. Plant Physiology, Washington, v. 4, n. 94, p. 1743-1747, Dec. 1990.

ALONI, R. Role of auxin and gibberellin in differentiation of primary phloem fibers. Plant Physiology, Washington, v. 4, n. 63, p. 609-614, Apr. 1979.

ALONI, R. Role of cytokinin in differentiation of secondary xylem fibers. Plant Physiology, Washington, v. 6, n. 70, p. 1631-1633, Dec. 1982.

ATAL, C. K. Effect of gibberellin on the fibers of hemp. Economic Botany, Bronx, v. 15, n. 2, p. 133-139, Apr. 1961.

BIEMELT, S.; TSCHIERSCH, H.; SONNEWALD, U. Impact of altered gibberellin metabolism on biomass accumulation, lignin biosynthesis, and photosynthesis in transgenic tobacco plants. Plant Physiology, Washington, v. 135, p. 254-265, May 2004.

Cerne, Lavras, v. 17, n. 3, p. 369-375, jul./set. 2011
BRASIL, M. A. M.; FERREIRA, M. Variação da densidade básica e das características das fibras em Eucalyptus grandis Hill ex Maiden ao nível do DAP. IPEF, Piracicaba, n. 5, p. 81-90, 1972.

BREMMER, J. M. Inorganic forms of nitrogen. In: BLACK, C. A.; EVANS, D. D.; EVANS, J. L.; WHILE, J. L.; ENSMINGER, J. E.; CLARK, F. E. (Eds.). Methods of soil analysis. Madison: American Society of Agronomy, 1965. p. 1179-1237.

BROWNING, B. L. Methods of wood chemistry. New York: Interscience, 1967.377 p.

DALESSANDRO, G.; ROBERTS, L. W. Induction of xylogenesis in pith parenchyma explants of Lactuca.

American Journal of Botany, Saint Louis, v. 58, n. 5, p. 378$385,1971$.

FRANKLIN, G. L. Preparation of thin sections of synthetic resins and wood: resin composites, and a new macerating method for wood. Nature, London, v. 155, p. 51, Jan. 1945.

LI, Z. D. Study on the influence of plant hormones in the growth and development of ramie. In: . Collection of academic theses on ramie for Li Zongdao. Beijing: Hunan Science and Technology, 1992. p. 251-257.

LIU, X. L.; COVINGTON, M. F.; FANKHAUSER, C.; CHORY, J.; WAGNER, D. R. ELF3 encodes a circadian clock-regulated nuclear protein that functions in an arabidopsis $P H Y B$ signal transduction pathway. Plant Cell, Oxford, v. 13, n. 6, p. 1293-1304, June 2001.

NAKAMURA, T.; SAOTOME, M.; ISHIGURO, Y.; ITOH, R.; HIGURASHI, S.; HOSOMO, M.; ISHII, Y. The effects of $\mathrm{GA}_{3}$ on weeping of growing shoots of the Japanese cherry, Prunus spachiana. Plant Cell Physiology, Dordrecht, v. 35, n. 3, p. 523-527, Mar. 1994.

PHARIS, R. P.; JENKINS, P. A.; AOKI, H.; SASAA, T. Hormonal physiology of wood growth in Pinus radiata D. Don: effects of gibberellin A4 and the influence of abscisic acid upon[3 H] gibberellin A4 metabolism. Australian Journal Plant Physiology, Melbourne, v. 8, n. 6, p. 559-567, 1981. 
SAKS, Y.; FEIGENBAUM, P.; ALONI, R. Regulatory effect of cytokinin on secondary xylem fiber formation in na in vivo system. Plant Physiology, Washington, v. 76, n. 3, p. 638-642, Nov. 1984.

SANTOS, S. R. Influência da qualidade da madeira de híbridos de Eucalyptus grandis x Eucalyptus urophylla e do processo Kraft de polpação na qualidade da polpa branqueada. 2005. 178 p. Dissertação (Mestrado em Recursos Florestais) - Escola Superior de Agricultura "Luiz de Queiroz", Piracicaba, 2005.

WANG, H. M.; HE, S. S. The influence of some plant growth regulators to rami fiber yield and quality. China Fiber Crops, Beijing, v. 14, n. 4, p. 39-40, 1992.

Cerne, Lavras, v. 17, n. 3, p. 369-375, jul./set. 2011 